\title{
EDITORIAL
}

\section{More Sloppy Reasoning about Survival}

\author{
Stephen E. Braude \\ https://doi.org/10.31275/20212251 \\ Creative Commons License CC-BY-NC \\ In my writings on the evidence for postmortem \\ survival I've made no secret of the fact that I \\ consider much of the literature on the subject to \\ be very shabby, usually because the authors are \\ empirically myopic or inferentially challenged.
}

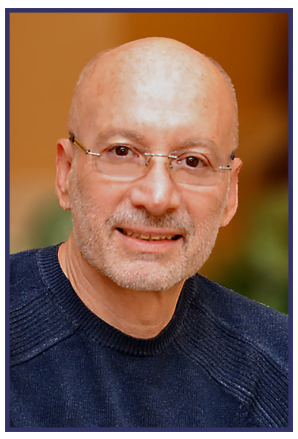
That is, writers on survival notoriously ignore or treat very superficially relevant areas of research having their own extensive literatures (e.g., on dissociation, savantism, prodigies, gifted underachievers, and language mastery), and too often they seem unable to formulate valid arguments. In 2003 I explored these deficiencies in great detail (Braude, 2003). Here, l'd like simply to comment on a particular class of confusions and a recent eruption of nonsequiturs.

Because the errors I'm about to discuss have been described in detail before, not just by me, but at least as long ago as 1961 (Ducasse, 1961), I find it particularly disheartening to see veteran researchers continuing to make the same old mistakes. And there's one argument in particular that periodically rears its ugly head. It goes like this:

The evidence for clairvoyance, telepathy, and precognition all show that consciousness can acquire information that is not available to the body's sensory system. Similarly, the evidence for psychokinesis shows that consciousness can influence physical events in ways that are not possible for the human motor system. Therefore, consciousness can operate independently of the body. And that's a sufficient condition for survival to be a possibility.

I've recently encountered this line of reasoning from several sources, and I'm puzzled by its appeal. In particular, I'm struck by the 
glaring nonsequitur italicized in the passage above. The problem is this. When we identify examples of ESP or PK, either in the lab or in life, we attribute those achievements, as we should, to embodied human beings whose mentality is intimately tied to the integrity of the brain and other bodily organs. That's not to say that mentality necessarily depends on bodily processes. That's the main question in survival research, and I'm prepared to leave that as an open question. In fact, as the philosopher J. M. E. McTaggart noted,

Even if the brain is essential to thought while we have bodies, it would not follow that when we ceased to have brains we could not think without them. ... It might be that the present inability of the self to think except in connexion with the body was a limitation which was imposed by the presence of the body, and which vanished with it. (McTaggart, 1930, p. 106)

And along the same lines,

It may be just the existence of the body which makes ... other ways [of getting data] impossible at present. If a man is shut up in a house, the transparency of the windows is an essential condition of his seeing the sky. But it would not be prudent to infer that, if he walked out of the house, he could not see the sky because there was no longer any glass through which he might see it. (McTaggart, 1930, p. 105)

We can supplement McTaggart's point with a contemporary analogy. Consider the case of portable electronic devices that can operate either on battery power or through a connection to AC lines. Typically, the powerline connections allow the portable device to perform functions it might not be able to perform on its own, or to perform functions better than it can perform on its own. But perhaps more important, powerline connections also impose constraints on the portable device's function, constraints which it lacked as a stand-alone device. Of course, they make the device less portable. But they also render the portable device vulnerable to processes (e.g., power surges or fluctuations) which can alter or impair its performance and even disable it. For example, some audio equipment sounds better on its battery power than when connected to AC lines. So perhaps like the 
portable device's connection to a wall outlet, physical embodiment would simply be one possible medium for human cognitive expression. And like running on battery power, disembodied existence might be another.

So when we consider the evidence for antemortem ESP and PK, we must concede that those psi experiences, along with the rest of our mental states, are mediated by the body. The parapsychological evidence is simply not evidence of mental independence from the body.

We can perhaps see this even more clearly in connection with out-of-body experiences (OBEs), because OBEs offer an even greater temptation to confuse mind-body distinctness with mind-body independence. OBE externalists maintain that a nonphysical element of being (the mind or a secondary or subtle body, and vehicle for consciousness) literally travels to and exists at locations outside the OBEr's physical body. That appears to be dramatically illustrated in so-called reciprocal cases, in which people report seeing the OBEr at the site that person is ostensibly visiting. Accordingly, some claim that OBEs demonstrate a profound distinction between mind and body, and they erroneously conclude that human beings aren't simply physical systems, and (even more suspiciously) that our characteristic mental activity can continue after bodily death.

The mistake here is painfully elementary. The most that can be said for externalism is that it's compatible with the survival hypothesis. But of course, that result is clearly underwhelming. Externalism might be compatible with survival even if there are good reasons for concluding that the survival hypothesis is false. For example, Mark Woodhouse (who actually argues for externalism) comments,

Externalism does not entail anything about survival of bodily death, except that it does not rule it out. It is a tremendous conceptual jump from, say, a 30-minute OBE to immortality. (Woodhouse, 1994, p. 14)

Harvey Irwin concurs. He writes,

Even if OBE research should support the existence of a nonphysical element of being, it might not bear directly upon the issue of whether this element is immortal. (Irwin, 1985, p. 25) 
Echoing C. J. Ducasse (Ducasse, 1961, p. 164), he continues,

it should not be assumed that during life the nonphysical element animates the body. In fact the reverse may be the case, so that destruction of the body occasions the death of the nonphysical element. (Irwin, 1985, pp. 25-26)

Therefore, to show that externalism actually supports (or more strongly, entails) a survival hypothesis, more needs to be said. We must ask: Why exactly would the distinctness of mind from body lead us to accept the survival hypothesis? As Woodhouse, Irwin, and others have noted, it's not enough simply to claim that mind and body are distinct. What matters is the way they differ.

Ducasse saw this clearly. He noted that externalists typically embrace the animistic view that the physical body is causally dependent on the thing that leaves the body during OBEs. They'd say that under normal circumstances, the secondary (or astral) body animates the physical body by being infused throughout the physical body (or colocated with it). And during OBEs the secondary body animates the physical body in a different way, either through its connection with a "silver cord" (according to some accounts), or by means of an invisible and currently unidentified connection. But, Ducasse noted, it

could equally be that the animation is in the converse direction, i.e., that death of the body entails death of the conscious "double" whether the latter be at the time dislocated from or collocated with the former. (Ducasse, 1961, p. 164)

Ducasse is clearly correct. Mind may be causally dependent on body even if mind and body are distinct. But then it's clear that the link between mind-body distinctness and mind-body independence is tenuous at best. To make this point even more vividly, consider the relation of an object to its shadow. First, the object and its shadow occupy different locations in space, just as the mind and physical body purportedly occupy different locations during OBEs. Moreover, shadows are causally efficacious; they can have effects on the world around them. For example, shadows will lower the ambient temperature and affect light meter readings at their locations. Similarly, externalists claim that, 
in reciprocal OBEs and in the intriguing Osis-McCormick experiment with Alex Tanous (Osis \& McCormick, 1980), the traveling mind affects the world at remote locations. In reciprocal cases observers at the remote locations report seeing the OBEr, and in the Osis-McCormick experiment Tanous apparently activated a strain-gauge at the location he ostensibly "visited." But then, even if externalists are correct that during OBEs the mind exists apart from the physical body and can affect the world at that place, that won't advance the case for survival. After all, since a shadow will cease to exist when the object casting the shadow ceases to exist, for all we know the mind may be similarly dependent on the body. The question for the externalist at this point must therefore be: Is there any reason for thinking that the mind is more independent of the body than the body's shadow? As far as I can see, nothing in the literature on OBEs provides such a reason.

Some externalists adopt a strong substance-dualist variant of the externalist position. For example, Robert Almeder writes,

Obviously, if people can literally leave their bodies, then human personality is something distinct from the body itself. The person who leaves her or his body and then returns to it must be something more than just the very complex organism whose properties are revealed by physical science. Such a person would need to be some sort of nonphysical being that lives in the body. (Almeder, 1992, p. 163)

And later,

the evidence [for veridical OBEs] strongly warrants our endorsing some form of mind-body dualism that eschews a pure reduction of human personality to bodily existence as we know it. ... [W] have in these best cases enough in the way of "proof" to justify a rational belief in some form of postmortem personal survival. (Almeder, 1992, p. 194)

Now we've already seen that mind and body may be distinct even if they're not independent. Almeder adds to this a related implausibilitynamely, that mind-body distinctness supports adopting a form of Cartesian (or substance) dualism, according to which mind and body are distinct kinds of things, rather than (say) different levels of 
description, neither of which reduces to the other without residue. Part of the problem here is that there are almost as many forms of dualism as there are flavors of ice cream. And many philosophers take mind and body to be different while at the same time holding that mind can't exist without the body. In fact, some of those are nonreductive physicalists: They claim that the only "stuff" in nature is physical, but at the same time they deny that the mental reduces to the physical. Instead, they subscribe to a kind of substance-monism according to which the world comprises fundamentally physical things, even though our descriptions of mental events can't be translated fully into physical terms. Thus, they subscribe to a kind of property-dualism rather than a strong substance-dualism. And it shows again that one can take mind and body to be distinct while rejecting the survival hypothesis.

For example, epiphenomenalists argue that mental events are merely byproducts of physical events. Although they differ from physical events, mental events are entirely causally dependent on underlying physical processes, and in fact mental events have no causal powers of their own. For example, although it seems as if our volitions cause our actions, the apparent efficacy of our volitions is misleading. Both our actions and our volitions are caused by underlying physical events. Volitions, according to this view, are merely symptoms of that underlying causal network and (as it were) signals of the physical events that follow. So epiphenomenalists are happy to accept that the relation of body to mind is analogous to the relation between a thing and its shadow.

We should also observe an important point about the connection between externalism and mind-body dualism. As we've seen, some find it tempting to suppose that externalism presupposes (or at least supports) a strong substance dualism, according to which mind and body are radically different kinds of entities. That seems to be Almeder's view, and it's why he contends that the "person who leaves her or his body and then returns to it . . . would need to be some sort of nonphysical being that lives in the body." Now historically, at least, substance dualists have maintained that one crucial difference between mind-stuff and body-stuff is that the latter is extended in space whereas the former is nonextended. Thereafter, opinions diverge. For example, Descartes claimed (notoriously) that, despite this difference, mind and 
body interact by means of efficient causality (i.e., like billiard balls). However, his follower, Malebranche, endorsed the parallelist view that mind-body interaction was merely apparent causality, with true causal connections being traceable only to God.

But these differences needn't concern us here. What matters is that, contrary to what some think, externalism presupposes (or implies) neither classic Cartesian dualism nor any of its successors. Even if we grant that during veridical OBEs the mind, or some aspect of oneself (or one's consciousness), severs its normal connection with the body, nothing follows about what sort of stuff this separated thing might be. Actually, for reasons I explain below, it may follow that whatever leaves the body is not an unextended Cartesian mind. But apart from that, externalism doesn't commit one to any particular view as to what kind of substance the mind (or the relevant aspect of consciousness) is. Externalists need only claim that this thing has certain functional properties-for example, the ability to mediate the OBEr's apparent perceptions of remote locations. It can remain an open question whether this thing is nonphysical or possibly a kind of material stuff not currently identified by science. That simply acknowledges a reasonable point widely accepted within the philosophy of mind: namely, that even if minds and bodies are not radically different types of hardware, they may still differ functionally. But if this is correct and externalism doesn't have to posit a mind-stuff that differs radically from body-stuff, then the inference from externalism to survival (made by Almeder and others) is weakened considerably.

Ironically, though, externalism seems incompatible with any dualism (such as Descartes's) according to which mind is nonspatial. For the Cartesian dualist, mind may be associated somehow with a body, and even interact causally with a body. However, mind is not contained in the body, because that requires having a location in space. According to the Cartesian dualist, the mind is nowhere in particular, or nowhere at all. Perhaps if Descartes had been familiar with the trendy terms of current physics, he would have said that mind is nonlocal. At any rate, the problem is this. Externalism holds that during OBEs a person's mental activity detaches from the body and travels somehow to a location different from that of the body. But since only something in space can be at a location, this thing can't be what many substance 
dualists say the mind is: an unextended nonphysical thing.

Of course, animists can avoid this last problem by positing secondary or subtle bodies that have some spatial properties. It's curious, then, that Almeder shows so little interest in that theoretical option. It might help flesh out his claim (pun intended) that minds (or perhaps persons) are both nonphysical and localizable.

But let's now set aside the issue of what flavor of dualism is suggested by OBEs. There's another major reason why survivalists are ill-advised to argue for their case by appealing to OBEs. If OBEs provide evidence for any kind of survival of bodily death, strictly speaking, it would be evidence only of short-term survival. OBEs provide no justification for assuming that mental activity could persist independently of the body for periods significantly longer than an OBE. Analogies are easy to come by. For example, a person's last breath may linger briefly after bodily death. But it will dissipate quickly, and certainly it won't persist indefinitely. Similarly, my farts can leave my body; they're distinct from my body; and they can affect the world outside my body. But they're also entirely causally dependent for their existence on my body. Now of course, farts can linger for a while after coming into existence. But despite an enormous database of human farts, we have no reason to anticipate the production of a fart everlasting, even if that remains an empirical possibility. So it seems that even under the most charitable of readings, the evidence from OBEs shows too little. It gives us no reason to believe that the mind is more substantial, resilient, and self-sustaining than a fart.

\section{REFERENCES}

Almeder, R. (1992). Death and personal survival: The evidence for life after death. Rowman \& Littlefield.

Braude, S. E. (2003). Immortal remains: The evidence for life after death. Rowman \& Littlefield. Ducasse, C. J. (1961). A critical examination of the belief in a life after death. Charles C. Thomas.

Irwin, H. J. (1985). Flight of mind: A psychological study of the out-of-body experience. Scarecrow Press.

McTaggart, J. M. E. (1930). Some dogmas of religion (2nd ed.). Thoemmes Press.

Osis, K., \& McCormick, D. (1980). Kinetic effects at the ostensible location of an out-ofbody projection during perceptual testing. Journal of the American Society for Psychical Research, 74(3), 319-329.

Woodhouse, M. B. (1994). Out-of-body experiences and the mind-body problem. New Ideas in Psychology, 12, 1-16. 